\title{
Quantifying choriocapillaris flow deficits using global and localized thresholding methods: a correlation study
}

\author{
Zhongdi Chu ${ }^{1}$, Qinqin Zhang ${ }^{1}$, Hao Zhou ${ }^{1}$, Yingying Shi ${ }^{2}$, Fang Zheng ${ }^{2}$, Giovanni Gregori ${ }^{2}$, \\ Philip J. Rosenfeld ${ }^{2}$, Ruikang K. Wang ${ }^{1,3}$ \\ ${ }^{1}$ Department of Bioengineering, University of Washington, Seattle, Washington, USA; ${ }^{2}$ Department of Ophthalmology, Bascom Palmer Eye \\ Institute, University of Miami Miller School of Medicine, Miami, Florida, USA; ${ }^{3}$ Department of Ophthalmology, University of Washington, Seattle, \\ Washington, USA
}

Correspondence to: Ruikang K. Wang. Department of Bioengineering, University of Washington, 372015 th Ave. NE, Seattle, Washington 98195 , USA. Email: wangrk@uw.edu.

Background: To investigate the correlation and agreement of two previously published choriocapillaris (CC) quantification methods using a normal database with swept-source optical coherence tomography angiography (SS-OCTA).

Methods: Normal adult subjects from all age groups imaged by SS-OCTA were used in this study. Each subject was imaged with $3 \mathrm{~mm} \times 3 \mathrm{~mm}$ and $6 \mathrm{~mm} \times 6 \mathrm{~mm}$ scan patterns centered on fovea, upon which en face CC images were generated by segmenting volumetric OCTA data. After signal compensation and removal of projection artifacts and noise, CC images were analyzed to identify flow deficits (FD) using two published methods. The first method utilized standard deviation from a young normal database (SD method) as the global thresholding while the second method utilized fuzzy C-means algorithm (FCM method) with local thresholding. Both methods segmented FDs from CC images and quantified FD density (FDD) and mean FD size (MFDS). In each $3 \mathrm{~mm} \times 3 \mathrm{~mm}$ scan, three regions were quantified: a $1 \mathrm{~mm}$ circle $\left(\mathrm{C}_{1}\right)$, a $1.5 \mathrm{~mm} \operatorname{rim}\left(\mathrm{R}_{1.5}\right)$ and a $2.5 \mathrm{~mm}$ circle $\left(\mathrm{C}_{2.5}\right)$. In each $6 \mathrm{~mm} \times 6 \mathrm{~mm}$ scan, five regions were quantified: $\mathrm{C}_{1}, \mathrm{R}_{1.5}, \mathrm{C}_{2.5}$, a $2.5 \mathrm{~mm}$ $\operatorname{rim}\left(\mathrm{R}_{2.5}\right)$ and a $5 \mathrm{~mm}$ circle $\left(\mathrm{C}_{5}\right)$. Spearman correlation and Bland-Altman plot analyses were conducted to compare the two methods.

Results: Data obtained from 164 normal subjects (age: 56 $\pm 19,59 \%$ females) were used in this study. Strong correlations were observed between the two methods in all comparisons (r: 0.78-0.94, all $\mathrm{P}<0.0001$ ). Overall MFDS provided higher or comparable correlation coefficients (r) compared to FDD. We have also observed stronger correlations in the central macula compared to parafoveal and perifoveal regions for both FDD and MFDS. In regions of $\mathrm{C}_{1}, \mathrm{R}_{1.5}$ and $\mathrm{C}_{2.5}, 6 \mathrm{~mm} \times 6 \mathrm{~mm}$ scans resulted in better agreement (smaller mean bias, similar or tighter limit of agreement) between the two methods for both FDD and MFDS compared to $3 \mathrm{~mm} \times 3 \mathrm{~mm}$ scans.

Conclusions: There are strong correlations and satisfactory agreement between SD method and FCM method. SD method requires the reference to a normal database for CC quantification while FCM does not. Both methods could be used for the analysis of CC FDs in clinical settings depending on specific study designs such as the availability of a normal database.

Keywords: Optical coherence tomography angiography (OCTA); swept source OCTA; choriocapillaris (CC); flow deficits

Submitted Nov 08, 2018. Accepted for publication Dec 12, 2018.

doi: 10.21037/qims.2018.12.09

View this article at: http://dx.doi.org/10.21037/qims.2018.12.09 


\section{Introduction}

Choriocapillaris (CC) plays an important role in multiple disease pathologies such as age-related macular degeneration (AMD), diabetic retinopathy (DR), uveitis, and glaucoma (1-7). Traditional dye-based angiography such as indocyanine green angiography has been used to image CC in vivo (8), but the limited resolution of dye based-angiography makes it impossible to achieve the level of CC visualization necessary for accurate quantification. Better visualization of CC in vivo and reliable quantification of the CC is needed to improve our understanding of the CC involvement in multiple eye diseases and help facilitate early diagnosis, improve our understanding of disease progression, and monitor treatment.

Recently, optical coherence tomography (OCT) and OCT based angiography (OCTA) $(9,10)$ have been introduced into clinical ophthalmology (11-22). OCTA is a non-invasive, safe, fast, and cost-effective technology that extracts the intrinsic signals due to moving particles, such as red blood cells, in functional vessels to achieve an in vivo angiogram. Due to its fast imaging speed (seconds), and high spatial resolution $(\sim 15-20 \mu \mathrm{m}$ laterally, $\sim \mu \mathrm{m}$ axially), a great deal of effort has been devoted to achieving accurate visualization and quantification of CC with OCTA (23-29). In particular, our group has reported two different methods to segment and quantify flow deficits (FDs) in en face CC images with swept-source OCTA (SS-OCTA). The first method (29) utilized a threshold based on the standard deviation (SD) calculated from CC images of 20 eyes randomly chosen from a group of 20-30 years old. This SD method has been used to quantify FDs in the $\mathrm{CC}$ in a normal database. One of its potential limitations is that it requires a collection of normal database as the reference. Therefore, it would not be able to directly translate between different scanning protocols, nor from one manufacturer's OCTA system to another. To mitigate this limitation, we have developed an alternative method (30) that utilized a fuzzy C-means (FCM) algorithm to segment and quantify CC. This FCM method was initially developed by Dunn in the early seventies (31) to cluster large datasets into different categories, and now it is widely used in bioinformatics and machine learning. The FCM was used in OCTA to assign each pixel into different memberships (CC flows or CC FDs), based on the histogram of the whole image (30). The advantage of the FCM method is that it can be applied across different OCTA systems or different scanning protocols.
In this study, we compared these two CC quantification methods, the SD method and the FCM method, using a normal database of 164 subjects to determine if the two methods produce comparable quantitative CC parameters. In addition to providing guidance on the use of these algorithms, a good agreement between the two methods would further validate the underlying approach to CC FDs quantification.

\section{Methods}

In this study, we used an existing SS-OCTA database available from the University of Miami and the University of Washington. The database was obtained from a crosssectional, study of normal eyes over a wide range of ages that was approved by the Institutional Review Board of Medical Sciences Subcommittee at University of Miami, Miller School of Medicine. The study at the University of Washington was also approved by the Institutional Review Board of Medical Sciences Subcommittee at University of Washington, Seattle. The tenets of the Declaration of Helsinki and the Health Insurance Portability and Accountability Act of 1996 regulations were followed. Informed consents were obtained from all subjects before participation. Subjects with a normal ocular history, no visual complains, and no identified optic disc, retinal, or choroidal pathology on examination were enrolled in the study between November 2016 to February 2018. 15 to 25 subjects were included in each decade ranging from 20 s to 80 s.

For all subjects, both eyes were scanned using the PLEX $^{\mathrm{TM}}$ Elite 9000 (Carl Zeiss Meditec, Dublin, CA), and both $3 \mathrm{~mm} \times 3 \mathrm{~mm}$ and $6 \mathrm{~mm} \times 6 \mathrm{~mm}$ SS-OCTA images centered on the fovea were acquired. The right eyes were selected for analysis by default unless poor signal strength $(<7)$ or severe motion artifacts were present. Due to the variability of the OCT signal strength among individual subjects, all the images were normalized to the signal strength of nine before OCTA maps were obtained for further CC analysis (32). A semi-automatic segmentation software (33) was then applied to both the OCT and OCTA images to produce a $20 \mu \mathrm{m}$ thickness CC slab located beneath Bruch's membrane. En face CC flow images were compensated using the corresponding en face structural images for any possible signal loss due to overlying anatomy (29). Subsequently, retinal projection artifacts were removed (32) before the CC OCTA images were further processed for quantification. 
$3 \mathrm{~mm} \times 3 \mathrm{~mm}$
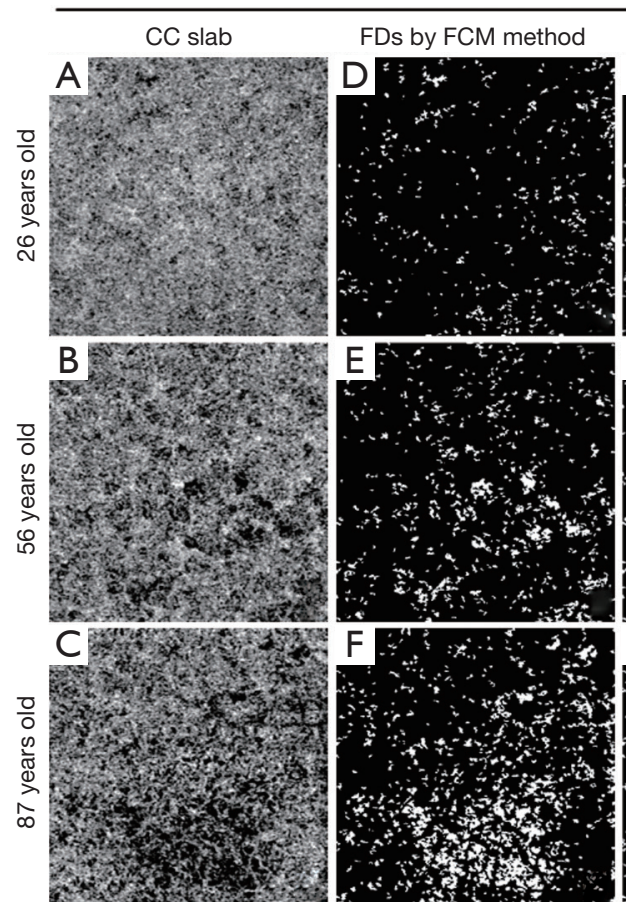
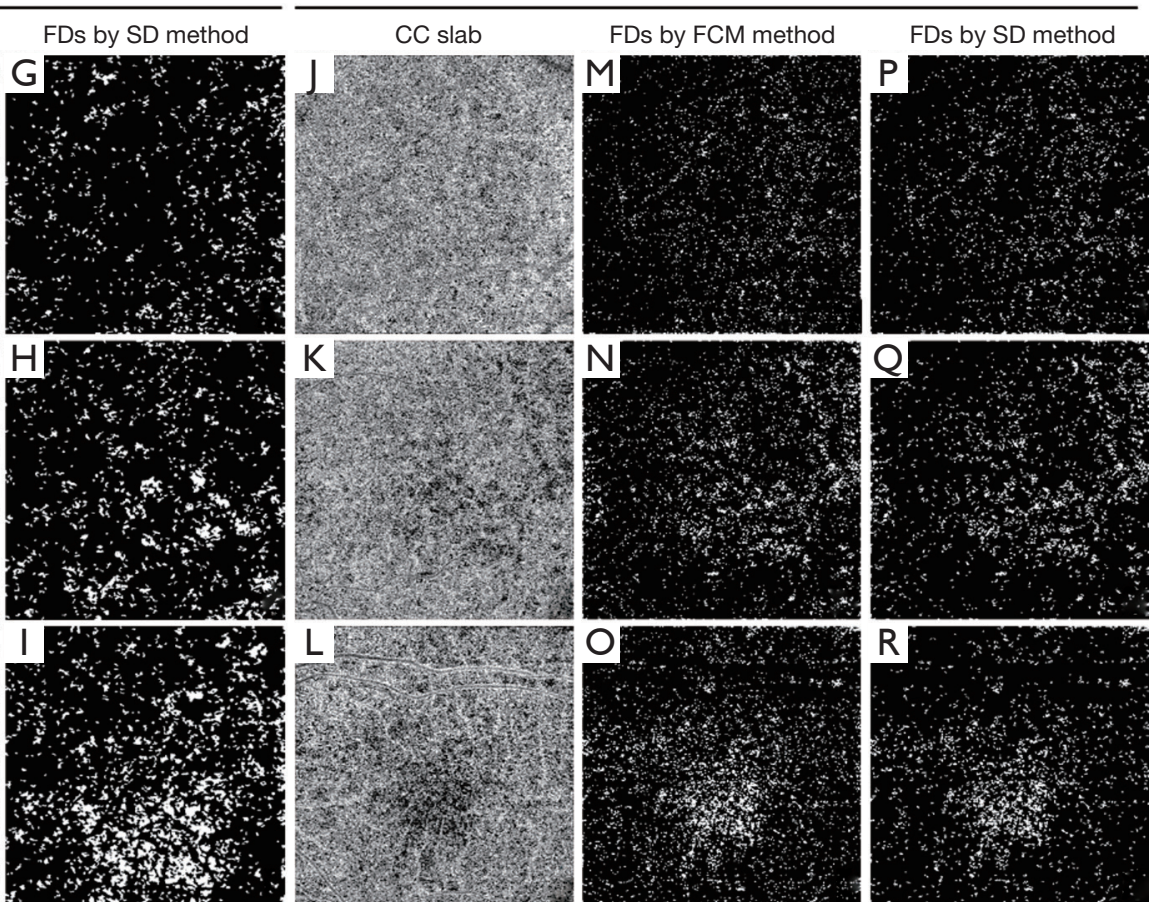

Figure 1 Examples of CC FD segmentations using the SD and FCM methods on $3 \mathrm{~mm} \times 3 \mathrm{~mm}$ and $6 \mathrm{~mm} \times 6 \mathrm{~mm} \mathrm{scans}$. (A,B,C) $3 \mathrm{~mm} \times$ $3 \mathrm{~mm}$ en face CC OCTA images of three subjects of different ages (26, 56, and 87 years old); (D,E,F) corresponding CC FD binary maps produced by the FCM method; (G,H,I) corresponding CC FD binary maps produced by SD method; (J,K,L) $6 \mathrm{~mm} \times 6 \mathrm{~mm}$ en face CC OCTA images of the same subjects; (M,N,O) corresponding CC FD binary maps produced by FCM method; (P,Q,R) corresponding CC FD binary maps produced by SD method. SD, standard deviation; FCM, fuzzy C-means; OCTA, optical coherence tomography angiography.

Two previously published methods, the SD and FCM methods, were applied to segment FDs (Figure 1). Briefly, in the SD method, the mean and SD from the reference normal database were used to determine a global threshold. Pixels with an intensity lower than one SD below its mean were segmented as FDs. In the FCM method, all pixels were clustered into memberships, CC vasculature and FDs, based on their intensity and the histogram distribution of the whole image. The number of memberships were automatically determined using the elbow method (34) and could vary from image to image. The first membership corresponds to the FDs, as it is the membership with lowest OCTA signal intensities.

Both methods generated CC FD binary maps for all subjects. A final step before the comparison was to remove FDs with an equivalent diameter smaller than $24 \mu \mathrm{m}$ from the CC FD maps, since these are smaller than the estimated inter-capillary distance (ICD) and are likely to represent noise $(30,35)$. Subsequently, FD density (FDD) and mean FD size (MFDS) (30) were calculated based on the respective
CC FD binary maps (Figure 1D, E, F, G, H,I,M,N,O,P,Q,R). In each $3 \mathrm{~mm} \times 3 \mathrm{~mm}$ scan, we quantified three regions centered at the fovea: a $1 \mathrm{~mm}$ circle $\left(\mathrm{C}_{1}\right)$, a $1.5 \mathrm{~mm}$ rim $\left(\mathrm{R}_{1.5}\right)$ and a $2.5 \mathrm{~mm}$ circle $\left(\mathrm{C}_{2.5}\right)$. Similarly, in each $6 \mathrm{~mm} \times 6 \mathrm{~mm}$ scans, we quantified five regions centered at the fovea: $\mathrm{C}_{1}, \mathrm{R}_{1.5}, \mathrm{C}_{2.5}$, a $2.5 \mathrm{~mm}$ rim $\left(\mathrm{R}_{2.5}\right)$ and a $5 \mathrm{~mm}$ circle $\left(\mathrm{C}_{5}\right)$. Positions of all quantified circles and rims are illustrated in Figure 2. Fovea positions were identified using a method previously described (36).

Statistical analyses were performed using MATLAB (R2016b; MathWorks, Inc., Natick, Massachusetts, USA) and Prism (GRAPHPAD software, San Diego, CA, USA). The nonparametric Spearman correlations and BlandAltman plots were used to describe the agreement between the methods (37). Repeatability was quantified as the coefficient of variation (CV) (38).

\section{Results}

We first used a published dataset of 10 normal subjects 

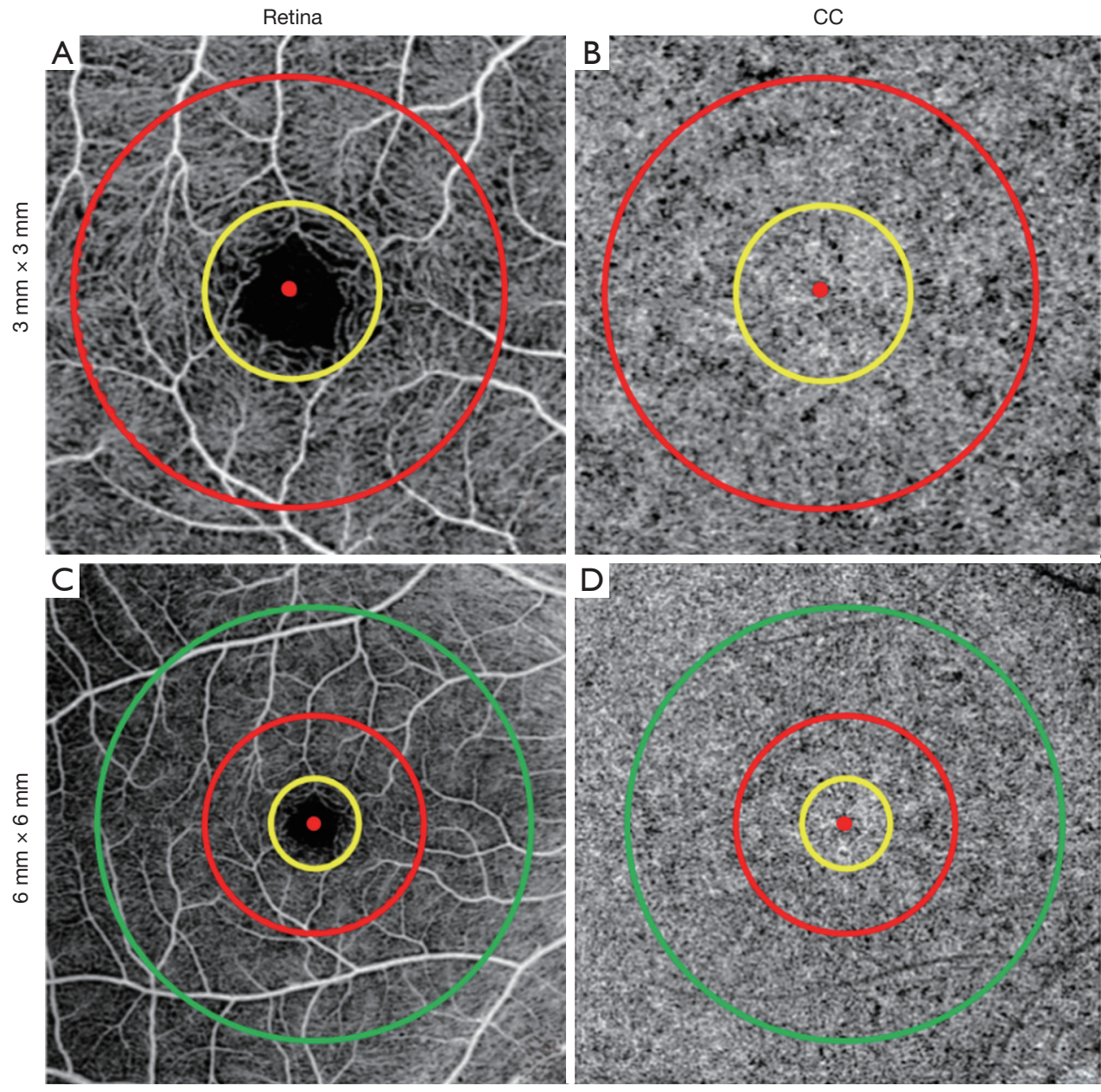

Figure 2 Illustration of the different CC regions that were quantified. (A) $3 \mathrm{~mm} \times 3 \mathrm{~mm}$ en face retina OCTA image, red dot shows the position of fovea, yellow circle represents the $1 \mathrm{~mm}$ diameter circle $\left(\mathrm{C}_{1}\right)$ and the red circle represents the $2.5 \mathrm{~mm}$ diameter circle $\left(\mathrm{C}_{2.5}\right)$, the $1.5 \mathrm{~mm}$ rim $\left(\mathrm{R}_{1.5}\right)$ corresponds to the region between the $1 \mathrm{~mm}$ circle (yellow) and the $2.5 \mathrm{~mm}$ circle (red). (B) $3 \mathrm{~mm} \times 3 \mathrm{~mm}$ en face $\mathrm{CC}$ OCTA image with the same $C_{1}, R_{1.5}$, and $C_{2.5}$ regions. (C) $6 \mathrm{~mm} \times 6 \mathrm{~mm}$ en face retina OCTA image, red dot shows the position of fovea, green circle represents the $5 \mathrm{~mm}$ diameter circle $\left(\mathrm{C}_{5}\right)$ and the yellow and red circles correspond to the same $\mathrm{C}_{1}, \mathrm{R}_{1.5}$ and $\mathrm{C}_{2.5}$ regions as in $\mathrm{A}$, and the $2.5 \mathrm{~mm}$ rim $\left(\mathrm{R}_{2.5}\right)$ corresponds to the region between the $2.5 \mathrm{~mm}$ circle (red) and the $5.0 \mathrm{~mm}$ circle (green). (D) $6 \mathrm{~mm} \times 6 \mathrm{~mm}$ en face CC OCTA image with the same $\mathrm{C}_{1}, \mathrm{R}_{1.5}, \mathrm{C}_{2.5}, \mathrm{R}_{2.5}, \mathrm{C}_{5}$ regions. OCTA, optical coherence tomography angiography.

and 11 subjects with drusen secondary to AMD (29) to evaluate the intra-visit repeatability of both the SD and FCM methods (Table 1). Repeatability of the SD method and FCM methods was comparable for FDD measurements while the FCM method provided better repeatability for MFDS measurements. Both methods provided better repeatability in the normal subjects group compared with repeatability in the drusen subjects group.

We then used both the SD and FCM methods on a total of 164 eyes from 164 subjects (age: $56 \pm 19,59 \%$ females) from the normal database. Both $3 \mathrm{~mm} \times 3 \mathrm{~mm}$ and $6 \mathrm{~mm}$ $\times 6 \mathrm{~mm}$ OCTA datasets were analyzed using both methods for all 164 normal eyes. For the $3 \mathrm{~mm} \times 3 \mathrm{~mm}$ scans, FDD and MFDS were measured over three regions $\left(\mathrm{C}_{1}, \mathrm{R}_{1.5}\right.$, $\left.\mathrm{C}_{2.5}\right)$, while for the $6 \mathrm{~mm} \times 6 \mathrm{~mm}$ scans, five regions $\left(\mathrm{C}_{1}\right.$, $\mathrm{R}_{1.5}, \mathrm{R}_{2.5}, \mathrm{C}_{2.5}, \mathrm{C}_{5}$ ) were used.

To compare quantitative CC measurements of FDD and MFDS produced by two methods, we applied Spearman's correlation analysis and Bland-Altman agreement analysis. Figure 3 demonstrates these analyses of the FDD in the 
Table 1 Comparison of intra-visit repeatability of SD method and FCM method

\begin{tabular}{lccccc}
\hline \multirow{2}{*}{ Coefficient of variation } & \multicolumn{2}{c}{ FDD (\%) } & \multicolumn{2}{c}{ MFDS (\%) } \\
\cline { 2 - 5 } & SD method & FCM method & SD method & FCM method \\
\hline Normal & 5.68 & 4.58 & 4.87 & 2.80 \\
Drusen & 7.43 & 4.64 & 7.39 & 5.04 \\
\hline
\end{tabular}

SD, standard deviation; FCM, fuzzy C-means.

A
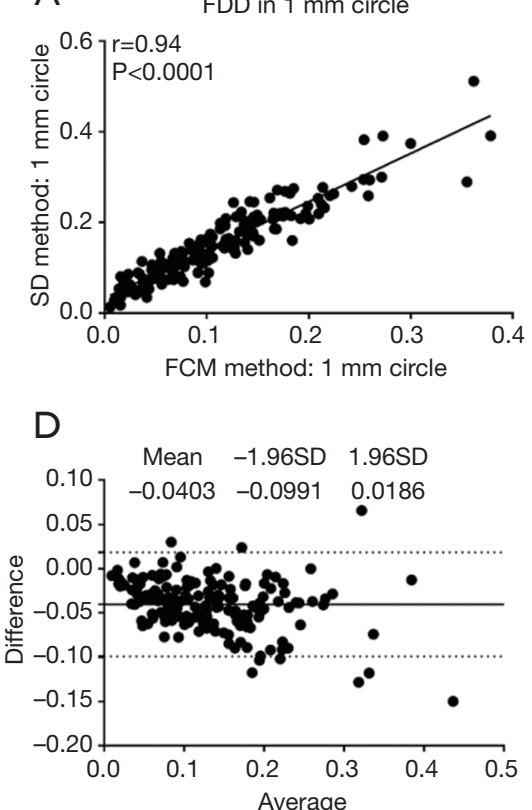

B

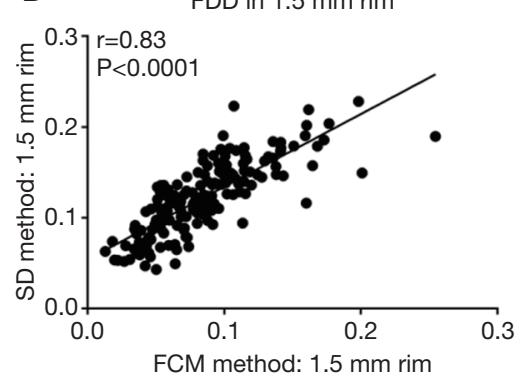

E

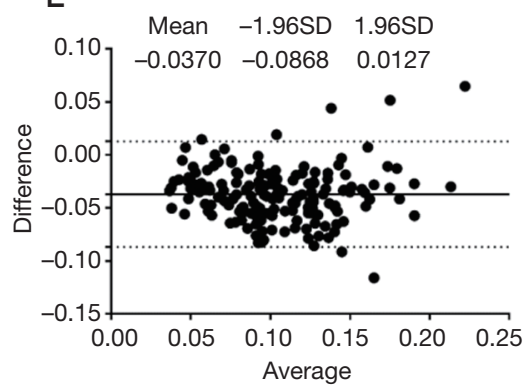

C

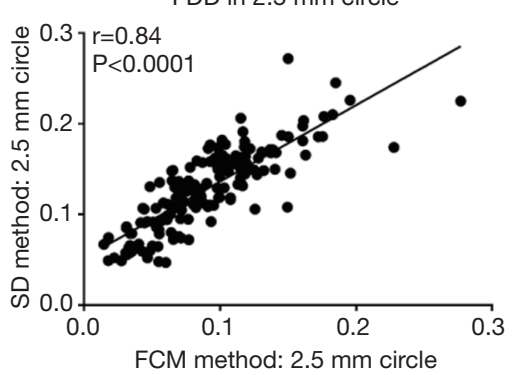

F

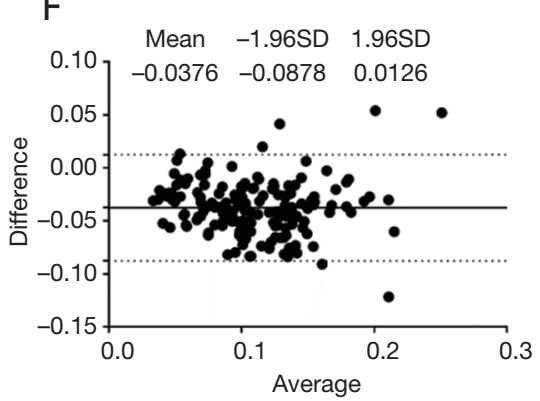

Figure $3 \mathrm{FDD}$ correlation and agreement analysis of $3 \mathrm{~mm} \times 3 \mathrm{~mm}$ scans in $\mathrm{C}_{1}(\mathrm{~A}, \mathrm{D}), \mathrm{R}_{1.5}(\mathrm{~B}, \mathrm{E})$ and $\mathrm{C}_{2.5}(\mathrm{C}, \mathrm{F})$.

$3 \mathrm{~mm} \times 3 \mathrm{~mm}$ scans. The correlation between two methods was the strongest in $\mathrm{C}_{1}(\mathrm{r}=0.94, \mathrm{P}<0.0001)$, followed by $\mathrm{C}_{2.5}(\mathrm{r}=0.84, \mathrm{P}<0.0001)$ and then $\mathrm{R}_{1.5}(\mathrm{r}=0.83, \mathrm{P}<0.0001)$. Overall, the FCM method produced lower FDD compared with the SD method. We have observed a mean bias of -0.0403 between the SD method and the FCM method in $\mathrm{C}_{1}$, with a limit of agreement (LOA) of -0.0991 to 0.0186 . $\mathrm{C}_{2}$ has a mean bias of -0.0376 and a LOA of -0.0878 to 0.0126 . In $R_{1.5}$, the mean bias is -0.0370 while the $\mathrm{LOA}$ is -0.0868 to 0.0127 . Similar trend was also found in MFDS in the $3 \mathrm{~mm} \times 3 \mathrm{~mm}$ scans (Figure 4). The correlation between the two methods was the strongest in $\mathrm{C}_{1}(\mathrm{r}=0.93$, $\mathrm{P}<0.0001)$, followed by $\mathrm{C}_{2.5}(\mathrm{r}=0.86, \mathrm{P}<0.0001)$ and then $\mathrm{R}_{1.5}$ $(\mathrm{r}=0.83, \mathrm{P}<0.0001)$. Overall, the FCM method produced larger MFDS compared with the SD method. There was a mean bias of $327.9 \mu^{2}$ (9.7 pixels) between the SD method and the FCM method in $\mathrm{C}_{1}$ [LOA: $-752.2 \mu \mathrm{m}^{2}$ (21.9 pixels) to $1,478 \mu^{2}$ (43.1 pixels)], a mean bias of $409 \mu^{2}(11.9$ pixels) in $\mathrm{C}_{2.5}$ [LOA: $-303.5 \mu^{2}$ (8.8 pixels) to $1,121 \mu \mathrm{m}^{2}$ (32.6 pixels)] and a mean bias of $284.6 \mu^{2}$ (8.3 pixels) in $\mathrm{R}_{1.5}$ [LOA: $341.9 \mu \mathrm{m}^{2}$ (9.9 pixels) to $911.1 \mu^{2}$ (26.5 pixels)]. Our data indicate that in the $3 \mathrm{~mm} \times 3 \mathrm{~mm}$ scans, the SD method resulted in smaller FDs compared to the FCM method, since the FCM method gave lower FDD yet larger MFDS on average. This suggests that the SD method could be more sensitive to smaller FDs while FCM method is more specific to larger FDs in $3 \mathrm{~mm} \times 3 \mathrm{~mm}$ scans.

In the $6 \mathrm{~mm} \times 6 \mathrm{~mm}$ scans, similar trends were observed for the correlations between the SD method and FCM method (Figures 5,6). Correlation was stronger in the central macular regions and weaker in parafoveal and perifoveal regions. For FDD in circles (Figure 5), the 

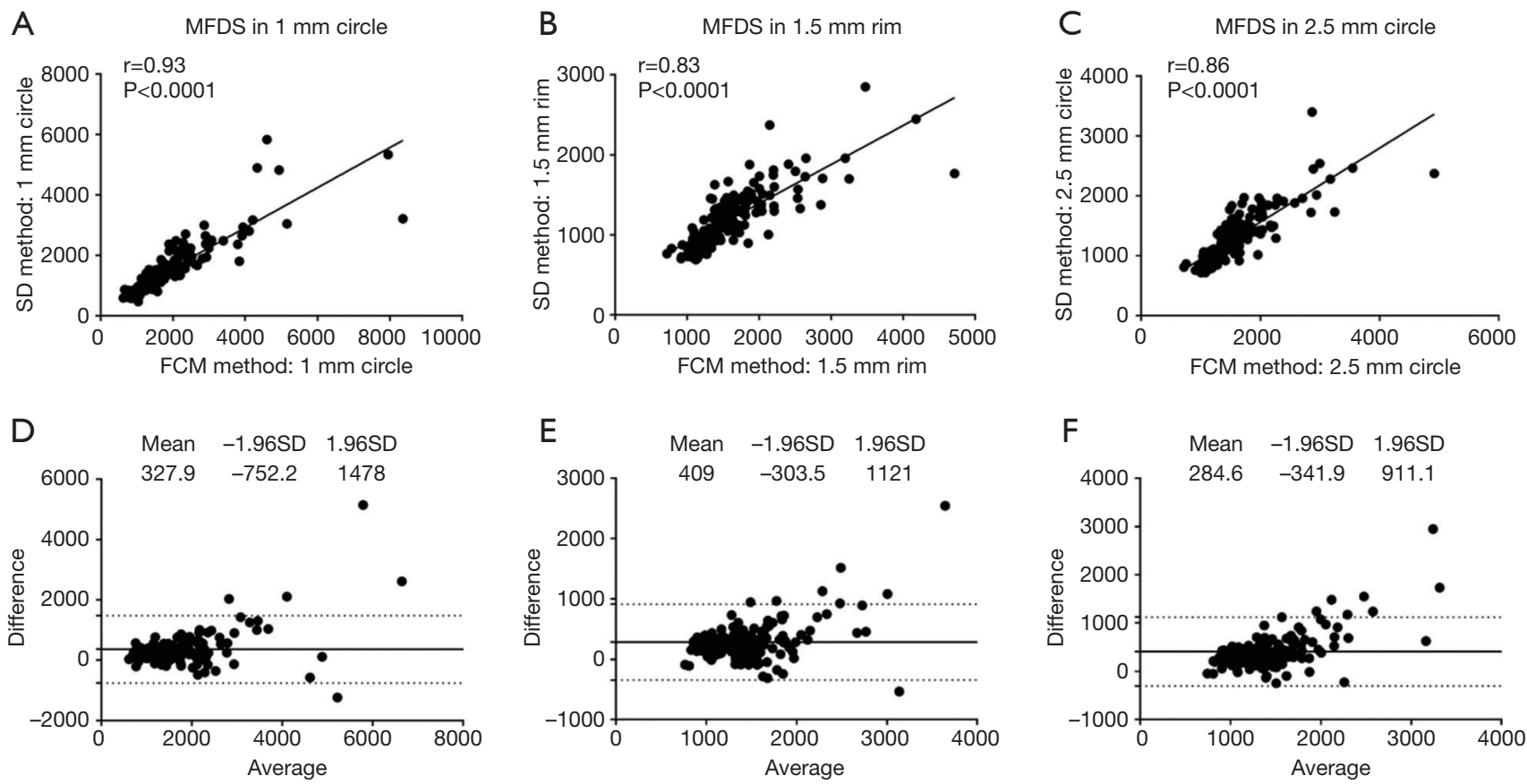

Figure 4 MFDS correlation and agreement analysis of $3 \mathrm{~mm} \times 3 \mathrm{~mm}$ scans in $\mathrm{C}_{1}(\mathrm{~A}, \mathrm{D}), \mathrm{R}_{1.5}(\mathrm{~B}, \mathrm{E})$ and $\mathrm{C}_{2.5}(\mathrm{C}, \mathrm{F})$.

correlation between two methods was the strongest in the central $\mathrm{C}_{1}(\mathrm{r}=0.94, \mathrm{P}<0.0001)$, followed by $\mathrm{C}_{2.5}(\mathrm{r}=0.86$, $\mathrm{P}<0.0001)$ and then $\mathrm{C}_{5}(\mathrm{r}=0.78, \mathrm{P}<0.0001)$. Similarly, in the rims, the $\mathrm{R}_{1.5}(\mathrm{r}=0.85, \mathrm{P}<0.0001)$ showed a stronger correlation than $\mathrm{R}_{2.5}(\mathrm{r}=0.81, \mathrm{P}<0.0001)$. On average, in all five regions, the FCM method resulted in higher FDD compared with the SD method. The mean bias in the $\mathrm{C}_{1}$ is 0.0188 (LOA: -0.0376 to 0.0752 ), 0.0212 for $\mathrm{C}_{2.5}$ (LOA: -0.0331 to 0.0757 ) and 0.0198 for $\mathrm{C}_{5}$ (LOA: -0.0226 to 0.0623 ). In the rims, the mean bias in $\mathrm{R}_{1.5}$ is 0.0218 (LOA: -0.0333 to 0.0769 ) and 0.0193 for $\mathrm{R}_{2.5}$ (LOA: -0.0196 to 0.0583). Similar trends for the correlations were found in MFDS as well (Figure 6). In circles, the correlation was the strongest in $\mathrm{C}_{1}(\mathrm{r}=0.93, \mathrm{P}<0.0001)$, followed by $\mathrm{C}_{2.5}$ $(\mathrm{r}=0.90, \mathrm{P}<0.0001)$ then $\mathrm{C}_{5}(\mathrm{r}=0.86, \mathrm{P}<0.0001)$. In rims, the correlation was stronger in $\mathrm{R}_{1.5}(\mathrm{r}=0.88, \mathrm{P}<0.0001)$ than $\mathrm{R}_{2.5}(\mathrm{r}=0.85, \mathrm{P}<0.0001)$. Overall, MFDS resulted in stronger correlations in all regions but $\mathrm{C}_{1}$ when compared with FDD. In terms of differences, the mean bias in $\mathrm{C}_{1}$ is $73.6 \mu \mathrm{m}^{2}$ (0.5 pixels) with a LOA of $-1,118 \mu \mathrm{m}^{2}$ (8.1 pixels) to $1,265 \mu^{2}$ (9.2 pixels), for $\mathrm{C}_{2.5}$, the mean bias is $36.5 \mu \mathrm{m}^{2}$ (0.3 pixels) and the LOA is $-669 \mu^{2}$ (4.9 pixels) to $597 \mu^{2}$ ( 4.3 pixels), for $\mathrm{C}_{5}$, the mean bias is $-116.1 \mu \mathrm{m}^{2}$ (0.8 pixels) and the LOA is $-669 \mu^{2}$ (4.9 pixels) to $597 \mu^{2}$ (4.3 pixels). In rims, the mean bias in $\mathrm{R}_{1.5}$ is $-116.1 \mathrm{~mm}^{2}$ (0.8 pixels) and the LOA is $-669 \mu^{2}$ (4.9 pixels) to $597 \mu^{2}$ (4.3 pixels), for $\mathrm{R}_{2.5}$, the mean bias is $-220.2 \mu \mathrm{m}^{2}$ (1.6 pixels) and the LOA is $-615.5 \mu^{2}$ (4.5 pixels) to $175.1 \mu \mathrm{m}^{2}$ (1.3 pixels).

\section{Discussion}

In this study, we have compared two methods for the quantification of CC FDs and found that both the SD and FCM methods provided good repeatability in normal subjects and drusen subjects, with the FCM method resulting in comparable or lower CV. We also demonstrated strong correlations between both methods for the quantitative CC parameters (r: 0.78-0.94, all $\mathrm{P}<0.0001$ ) derived from various regions of both the $3 \mathrm{~mm}$ $\times 3 \mathrm{~mm}$ scans and $6 \mathrm{~mm} \times 6 \mathrm{~mm}$ scans. Overall, the MFDS measurements resulted in comparable or better correlations compared to FDD measurements, especially in the $6 \mathrm{~mm} \times$ $6 \mathrm{~mm}$ scans.

Visualizing and quantifying CC have been a keen interest of many investigators $(24,25,29,37,39-45)$, especially since the recent technological advances of commercial OCTA systems. However, researchers should be cautious and vigilant while conducting quantitative analyses of CC using OCTA. There are a number of factors that could potentially compromise the integrity of CC quantification 
A
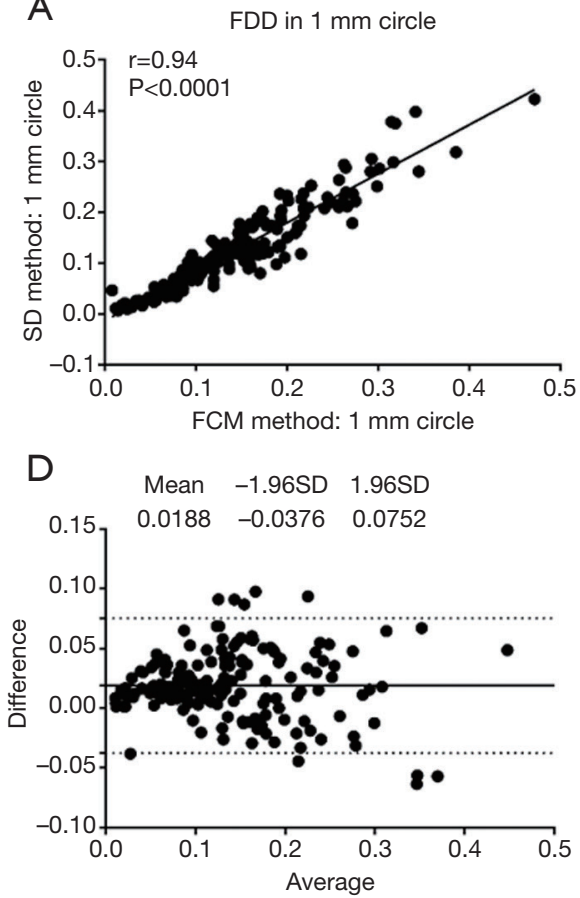

G
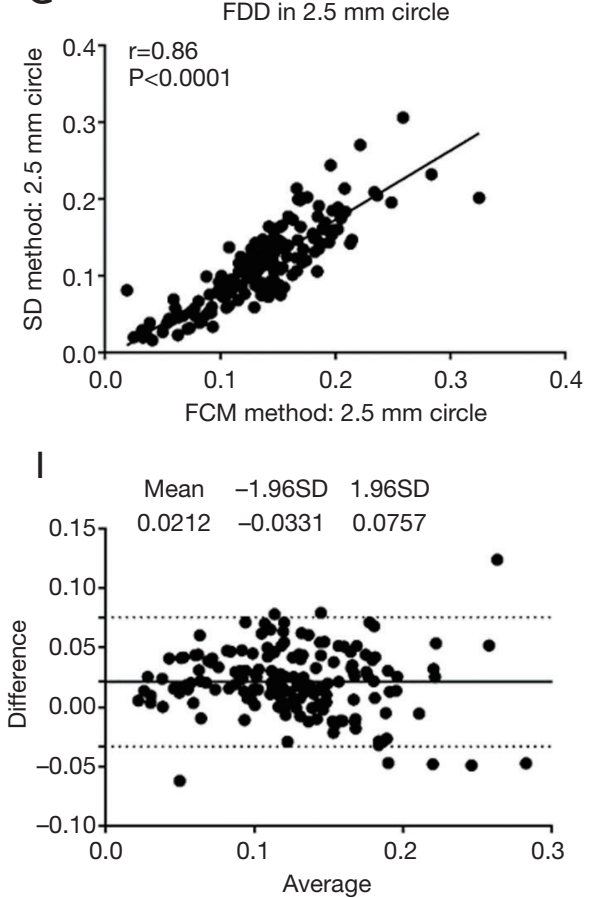

B
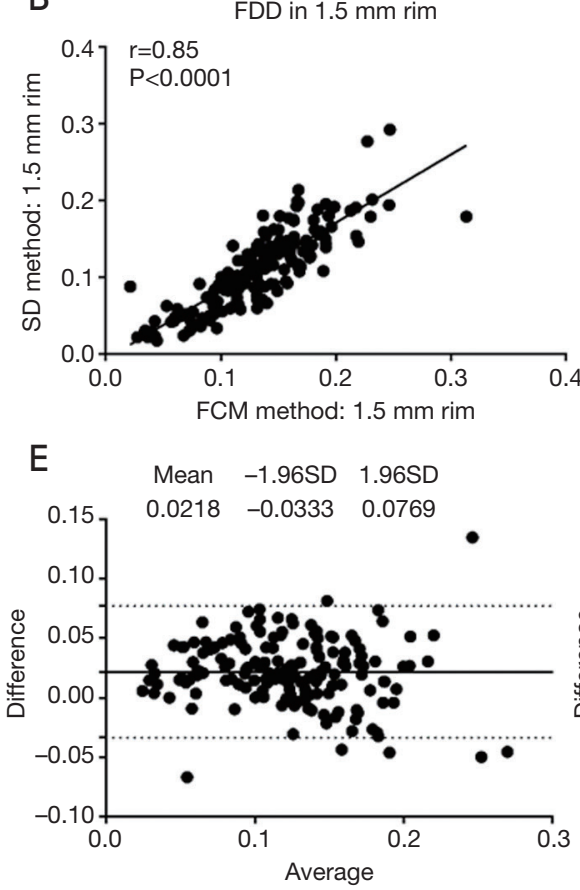

$\mathrm{H}$
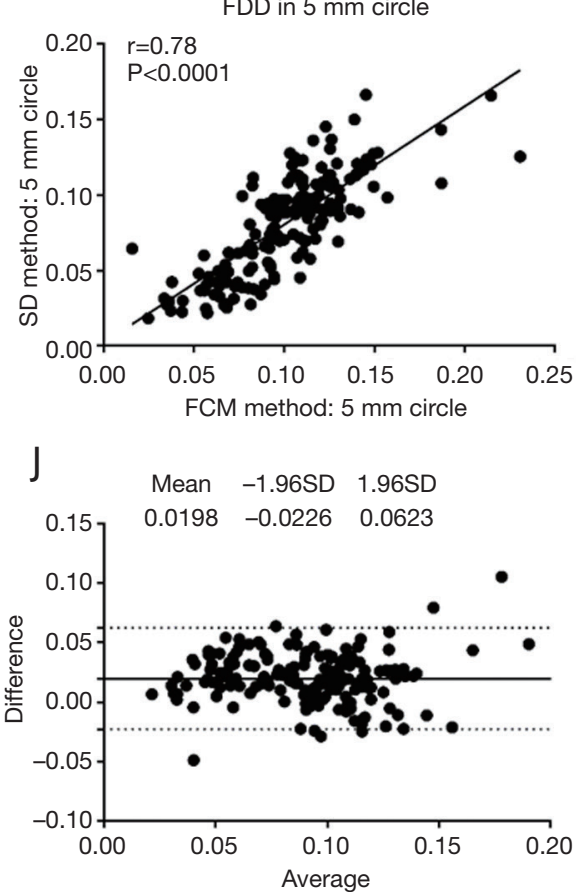

C
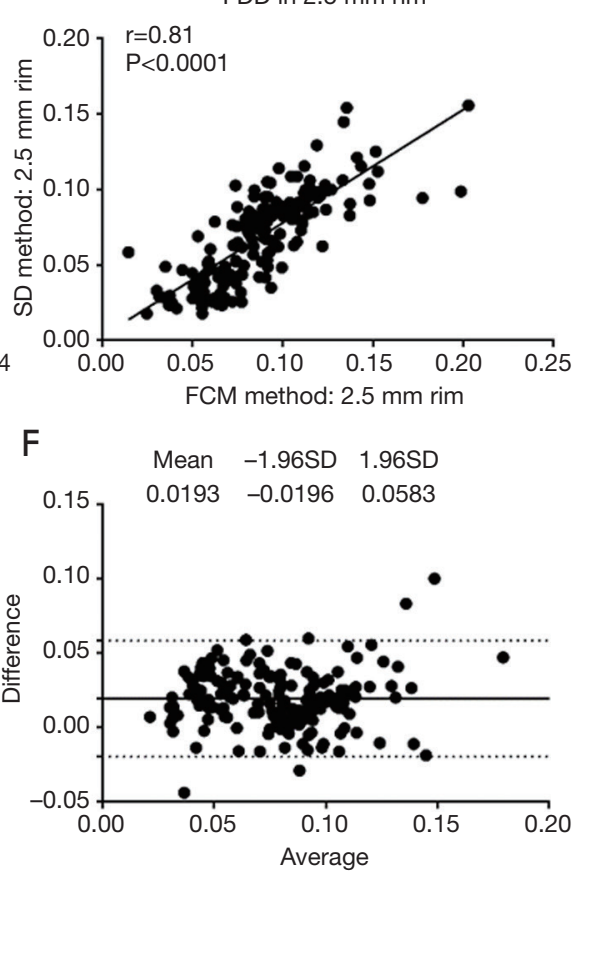

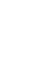



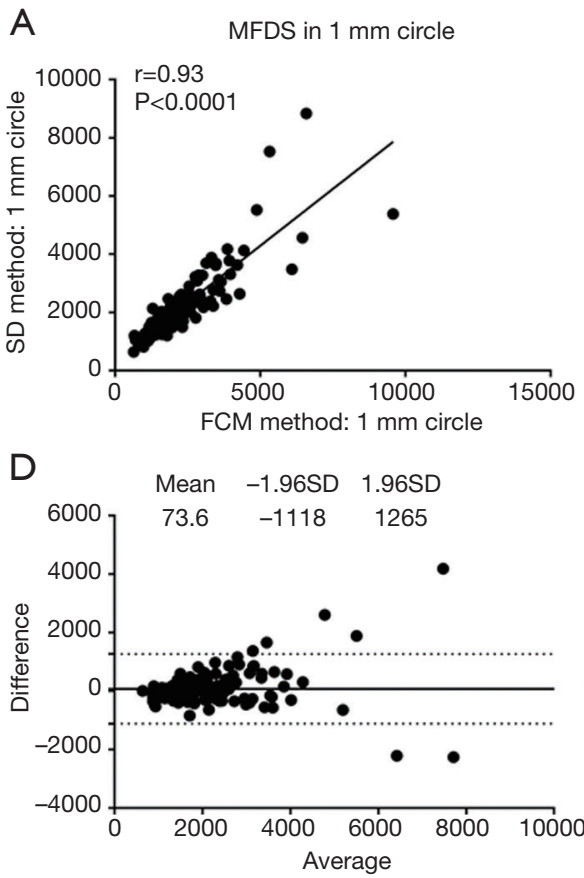

G
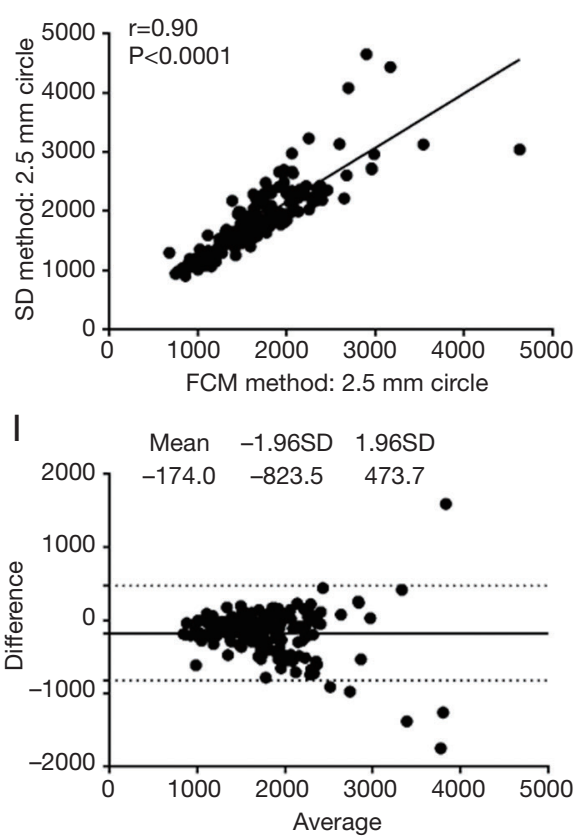

B

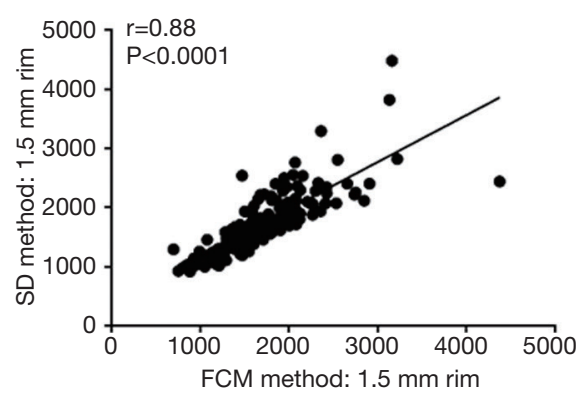

$\mathrm{E}$

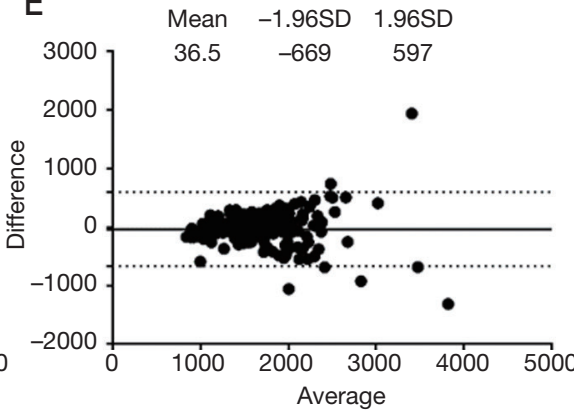

$\mathrm{H}$
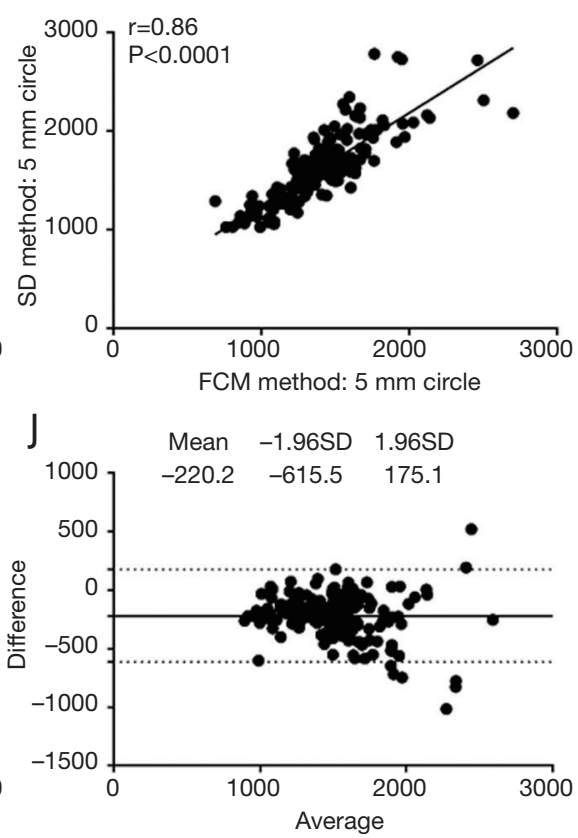

C
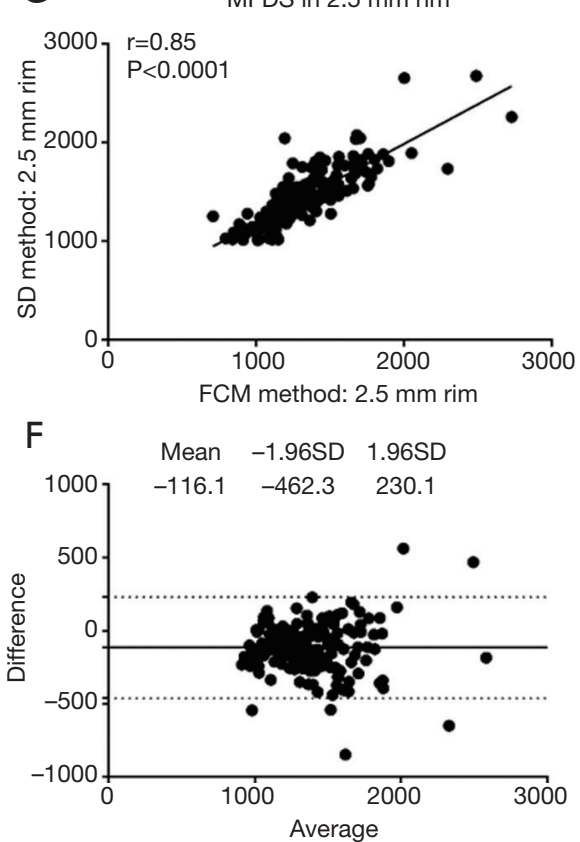

Figure 6 MFDS correlation and agreement analysis of $6 \mathrm{~mm} \times 6 \mathrm{~mm}$ scans in $\mathrm{C}_{1}(\mathrm{~A}, \mathrm{D}), \mathrm{R}_{1.5}(\mathrm{~B}, \mathrm{E}), \mathrm{R}_{2.5}(\mathrm{C}, \mathrm{F}), \mathrm{C}_{2.5}(\mathrm{G}, \mathrm{I})$ and $\mathrm{C}_{5}(\mathrm{H}, \mathrm{J})$.

signals in the CC. Both methods compared in this report showed satisfactory repeatability (FCM method all CV $\leq 5.04 \%$, SD method all $\mathrm{CV} \leq 7.43 \%$ ), strong correlations (all $\mathrm{P}<0.0001$, all $\mathrm{r}>0.83$ for $3 \mathrm{~mm} \times 3 \mathrm{~mm}$ and all $\mathrm{r}>0.78$ for $6 \mathrm{~mm} \times 6 \mathrm{~mm}$ ), and good agreement.
In summary, we have demonstrated strong correlations of quantitative CC metrics between the SD and FCM methods. Overall, the correlation was stronger in the central macular regions than in the parafoveal and perifoveal regions. For the same regions $\left(\mathrm{C}_{1}, \mathrm{R}_{1.5}, \mathrm{C}_{2.5}\right), 6 \mathrm{~mm} \times 6 \mathrm{~mm}$ 
scans resulted in similar or stronger correlations compared to $3 \mathrm{~mm} \times 3 \mathrm{~mm}$ scans. For either $3 \mathrm{~mm} \times 3 \mathrm{~mm}$ or $6 \mathrm{~mm}$ $\times 6 \mathrm{~mm}$ scan pattern, the MFDS measurements resulted in comparable or stronger correlations compared with the FDD measurements. In terms of agreement, $6 \mathrm{~mm} \times 6 \mathrm{~mm}$ scans resulted in smaller mean biases compared with the same regions $\left(\mathrm{C}_{1}, \mathrm{R}_{1.5}, \mathrm{C}_{2.5}\right)$ in the $3 \mathrm{~mm} \times 3 \mathrm{~mm}$ scans.

There are several limitations in the current study. Firstly, we lack a ground truth of accepted in vivo CC vasculature and FDs measurements for comparison with our quantitative analyses. However, currently there are no clinically available imaging techniques that can provide such a ground truth. It remains possible that future technological developments of adaptive optics OCTA or faster SS-OCTA instruments could solve this problem. Secondly, we only have compared the two methods on a normal population, and we did not include diseased population in the comparison part of this study. Future studies are needed to investigate the correlation and agreement between the SD method and the FCM method in diseased eyes. Regardless of these limitations, strong correlations and satisfactory agreements of quantitative CC parameters using the SD and FCM methods were observed. Both methods could be used for future analyses depending on specific study designs, such as availability of a normal database.

\section{Acknowledgements}

Funding: Research supported by grants from the National Eye Institute (R01EY024158, R01EY028753), the Salah Foundation, an unrestricted grant from the Research to Prevent Blindness, Inc., New York, NY, and the National Eye Institute Center Core Grant (P30EY014801) to the Department of Ophthalmology, University of Miami Miller School of Medicine. The funding organization had no role in the design or conduct of this research.

\section{Footnote}

Conflicts of Interest: Dr. Gregori, Dr. Wang and Dr. Rosenfeld received research support from Carl Zeiss Meditec, Inc. Dr. Gregori and the University of Miami coown a patent that is licensed to Carl Zeiss Meditec, Inc. Dr. Rosenfeld is a consultant for Achillion Pharmaceuticals, Acucela, Boehringer-Ingelheim, Carl Zeiss Meditec, Chengdu Kanghong Biotech, Ocunexus Therapeutics, Healios K.K, Hemera Biosciences, F. Hoffmann-La
Roche Ltd., Isarna Pharmaceuticals, Lin Bioscience, NGM Biopharmaceuticals, and Unity Biotechnology. Dr. Rosenfeld has equity interest in Apellis, Digisight, and Ocudyne. Dr. Wang discloses intellectual property owned by the Oregon Health and Science University and the University of Washington. Dr. Wang also receives research support from Tasso Inc., Moptim Inc., and Colgate Palmolive Company. He is a consultant to Insight Photonic Solutions, Kowa, and Carl Zeiss Meditec. The remaining authors have no conflicts of interest to declare.

Ethical Statement: The study was approved by the Institutional Review Board of Medical Sciences Subcommittee at University of Miami, Miller School of Medicine. The study at the University of Washington was also approved by the Institutional Review Board of Medical Sciences Subcommittee at University of Washington, Seattle. The tenets of the Declaration of Helsinki and the Health Insurance Portability and Accountability Act of 1996 regulations were followed. Informed consents were obtained from all subjects before participation.

\section{References}

1. Herbort C. Posterior uveitis: new insights provided by indocyanine green angiography. Nature Publishing Group, 1998.

2. Cao J, McLeod DS, Merges CA, Lutty GA. Choriocapillaris degeneration and related pathologic changes in human diabetic eyes. Arch Ophthalmol 1998;116:589-97.

3. Lutty G, Grunwald J, Majji AB, Uyama M, Yoneya S. Changes in choriocapillaris and retinal pigment epithelium in age-related macular degeneration. Mol Vis 1999;5:35.

4. Nazari H, Hariri A, Hu Z, Ouyang Y, Sadda S, Rao NA. Choroidal atrophy and loss of choriocapillaris in convalescent stage of Vogt-Koyanagi-Harada disease: in vivo documentation. J Ophthalmic Inflamm Infect 2014;4:9.

5. Whitmore SS, Sohn EH, Chirco KR, Drack AV, Stone EM, Tucker BA, Mullins RF. Complement activation and choriocapillaris loss in early AMD: implications for pathophysiology and therapy. Prog Retin Eye Res 2015;45:1-29.

6. Spraul CW, Lang GE, Lang GK, Grossniklaus HE. Morphometric changes of the choriocapillaris and the choroidal vasculature in eyes with advanced glaucomatous 
changes. Vision Res 2002;42:923-32.

7. Chen CL, Bojikian KD, Gupta D, Wen JC, Zhang Q, Xin C, Kono R, Mudumbai RC, Johnstone MA, Chen PP, Wang RK. Optic nerve head perfusion in normal eyes and eyes with glaucoma using optical coherence tomographybased microangiography. Quant Imaging Med Surg 2016;6:125.

8. Piccolino FC, Borgia L. Central serous chorioretinopathy and indocyanine green angiography. Retina 1994;14:231-42.

9. Chen C-L, Wang RK. Optical coherence tomography based angiography. Biomed Opt Express 2017;8:1056-82.

10. Kashani AH, Chen C-L, Gahm JK, Zheng F, Richter GM, Rosenfeld PJ, Shi Y, Wang RK. Optical coherence tomography angiography: A comprehensive review of current methods and clinical applications. Prog Retin Eye Res 2017;60:66-100.

11. Mariampillai A, Leung MK, Jarvi M, Standish BA, Lee K, Wilson BC, Vitkin A, Yang VX. Optimized speckle variance OCT imaging of microvasculature. Opt Lett 2010;35:1257-9.

12. Braaf B, Vienola KV, Sheehy CK, Yang Q, Vermeer KA, Tiruveedhula P, Arathorn DW, Roorda A, de Boer JF. Real-time eye motion correction in phase-resolved OCT angiography with tracking SLO. Biomed Opt Express 2013;4:51-65.

13. Huang Y, Zhang Q, Thorell MR, An L, Durbin MK, Laron M, Sharma U, Gregori G, Rosenfeld PJ, Wang RK. Swept-source OCT angiography of the retinal vasculature using intensity differentiation-based optical microangiography algorithms. Ophthalmic Surg Lasers Imaging Retina 2014;45:382-9.

14. Waheed NK, Moult EM, Fujimoto JG, Rosenfeld PJ. Optical coherence tomography angiography of dry agerelated macular degeneration. OCT Angiography in Retinal and Macular Diseases. Karger Publishers, 2016:91-100.

15. Kim AY, Chu Z, Shahidzadeh A, Wang RK, Puliafito CA, Kashani AH. Quantifying Microvascular Density and Morphology in Diabetic Retinopathy Using SpectralDomain Optical Coherence Tomography Angiography Quantifying Vascular Changes in DR With SD-OCTA. Invest Ophthalmol Vis Sci 2016;57:OCT362-70.

16. Pakzad-Vaezi K, Khaksari K, Chu Z, Van Gelder RN, Wang RK, Pepple KL. Swept-Source OCT Angiography of Serpiginous Choroiditis. Ophthalmol Retina 2018;2:712-9.

17. Kim AY, Rodger DC, Shahidzadeh A, Chu Z, Koulisis N, Burkemper B, Jiang X, Pepple KL, Wang RK, Puliafito CA. Quantifying Retinal Microvascular Changes in Uveitis
Using Spectral-Domain Optical Coherence Tomography Angiography. Am J Ophthalmol 2016;171:101-12.

18. Pepple KL, Chu Z, Weinstein J, Munk MR, Van Gelder RN, Wang RK. Use of En Face Swept-Source Optical Coherence Tomography Angiography in Identifying Choroidal Flow Voids in 3 Patients With Birdshot Chorioretinopathy. JAMA Ophthalmol 2018;136:1288-92.

19. Richter GM, Madi I, Chu Z, Burkemper B, Chang R, Zaman A, Sylvester B, Reznik A, Kashani A, Wang RK. Structural and Functional Associations of Macular Microcirculation in the Ganglion Cell-Inner Plexiform Layer in Glaucoma Using Optical Coherence Tomography Angiography. J Glaucoma 2018;27:281-90.

20. Zhang Q, Rezaei KA, Saraf SS, Chu Z, Wang F, Wang RK. Ultra-wide optical coherence tomography angiography in diabetic retinopathy. Quant Imaging Med Surg 2018;8:743.

21. Kam J, Zhang Q, Lin J, Liu J, Wang RK, Rezaei K. Optical coherence tomography based microangiography findings in hydroxychloroquine toxicity. Quant Imaging Med Surg 2016;6:178.

22. Zhang Q, Wang J, Wang RK. Highly efficient eigen decomposition based statistical optical microangiography. Quant Imaging Med Surg 2016;6:557.

23. Spaide RF. Choriocapillaris flow features follow a power law distribution: implications for characterization and mechanisms of disease progression. Am J Ophthalmol 2016;170:58-67.

24. Kurokawa K, Liu Z, Miller DT. Adaptive optics optical coherence tomography angiography for morphometric analysis of choriocapillaris. Biomed Opt Express 2017;8:1803-22.

25. Chu Z, Chen C-L, Zhang Q, Pepple K, Durbin M, Gregori G, Wang RK. Complex signal-based optical coherence tomography angiography enables in vivo visualization of choriocapillaris in human choroid. J Biomed Opt 2017;22:1-10.

26. Choi W, Mohler KJ, Potsaid B, Lu CD, Liu JJ, Jayaraman V, Cable AE, Duker JS, Huber R, Fujimoto JG. Choriocapillaris and choroidal microvasculature imaging with ultrahigh speed OCT angiography. PloS one 2013;8:e81499.

27. Gorczynska I, Migacz J, Jonnal R, Zawadzki R, Poddar R, Werner J. editors. Imaging of the human choroid with a 1.7 MHz A-scan rate FDML swept source OCT system. Ophthalmic Technologies XXVII; 2017: International Society for Optics and Photonics.

28. Uji A, Balasubramanian S, Lei J, Baghdasaryan E, 
Al-Sheikh M, Sadda SR. Choriocapillaris imaging using multiple en face optical coherence tomography angiography image averaging. JAMA Ophthalmol 2017;135:1197-204.

29. Zhang Q, Zheng F, Motulsky EH, Gregori G, Chu Z, Chen CL, Li C, de Sisternes L, Durbin M, Rosenfeld PJ, Wang RK. A Novel Strategy for Quantifying Choriocapillaris Flow Voids Using Swept-Source OCT Angiography. Invest Ophthalmol Vis Sci 2018;59:203-11.

30. Chu Z, Zhou H, Cheng Y, Zhang Q, Wang RK. Improving visualization and quantitative assessment of choriocapillaris with swept source OCTA through registration and averaging applicable to clinical systems. Sci Rep 2018;8:16826.

31. Dunn JC. A fuzzy relative of the ISODATA process and its use in detecting compact well-separated clusters. Journal of Cybernetics 1973:32-57.

32. Zhang Q, Zhang A, Lee CS, Lee AY, Rezaei KA, Roisman L, Miller A, Zheng F, Gregori G, Durbin MK, An L, Stetson PF, Rosenfeld PJ, Wang RK. Projection artifact removal improves visualization and quantitation of macular neovascularization imaged by optical coherence tomography angiography. Ophthalmol Retina 2017;1:124-36.

33. Yin X, Chao JR, Wang RK. User-guided segmentation for volumetric retinal optical coherence tomography images. J Biomed Opt 2014;19:086020.

34. Kodinariya TM, Makwana PR. Review on determining number of Cluster in K-Means Clustering. International Journal 2013;1:90-5.

35. Zhang Q, Shi Y, Zhou H, Gregori G, Chu Z, Zheng F, Motulsky EH, De Sisternes L, Durbin M, Rosenfeld PJ, Wang RK. Accurate estimation of choriocapillaris flow deficits beyond normal intercapillary spacing with swept source OCT angiography. Quant Imaging Med Surg 2018;8:658.

36. Wang F, Gregori G, Rosenfeld PJ, Lujan BJ, Durbin MK,

Cite this article as: Chu Z, Zhang Q, Zhou H, Shi Y, Zheng F, Gregori G, Rosenfeld PJ, Wang RK. Quantifying choriocapillaris flow deficits using global and localized thresholding methods: a correlation study. Quant Imaging Med Surg 2018;8(11):1102-1112. doi: 10.21037/qims.2018.12.09
Bagherinia H. Automated detection of the foveal center improves SD-OCT measurements of central retinal thickness. Ophthalmic Surg Lasers Imaging 2012;43:S32-7.

37. Altman DG, Bland JM. Measurement in medicine: the analysis of method comparison studies. The Statistician 1983;32:307-17.

38. Bland JM, Altman DG. Measurement error proportional to the mean. BMJ 1996;313:106.

39. Borrelli E, Souied EH, Freund KB, Querques G, Miere A, Gal-Or O, Sacconi R, Sadda SR, Sarraf D. Reduced choriocapillaris flow in eyes with type 3 neovascularization and age-related macular degeneration. Retina 2018;38:1968-76.

40. Moreira-Neto CA, Moult EM, Fujimoto JG, Waheed NK, Ferrara D. Choriocapillaris Loss in Advanced Age-Related Macular Degeneration. J Ophthalmol 2018;2018:8125267.

41. Al-Sheikh M, Falavarjani KG, Pfau M, Uji A, Le PP, Sadda SR. Quantitative Features of the Choriocapillaris in Healthy Individuals Using Swept-Source Optical Coherence Tomography Angiography. Ophthalmic Surg Lasers Imaging Retina 2017;48:623-31.

42. Klufas MA, Phasukkijwatana N, Iafe NA, Prasad PS, Agarwal A, Gupta V, Ansari W, Pichi F, Srivastava S, Freund KB. Optical coherence tomography angiography reveals choriocapillaris flow reduction in placoid chorioretinitis. Ophthalmol Retina 2017;1:77-91.

43. Gao SS, Patel RC, Jain N, Zhang M, Weleber RG, Huang D, Pennesi ME, Jia Y. Choriocapillaris evaluation in choroideremia using optical coherence tomography angiography. Biomed Opt Express 2016;8:48-56.

44. Spaide RF. Ising model of choriocapillaris flow. Retina 2018;38:79-83.

45. Borrelli E, Shi Y, Uji A, Balasubramanian S, Nassisi M, Sarraf D, Sadda SR. Topographic Analysis of the Choriocapillaris in Intermediate Age-related Macular Degeneration. Am J Ophthalmol 2018;196:34-43. 